\title{
Review of the cost of venous thromboembolism
}

This article was published in the following Dove Press journal:

ClinicoEconomics and Outcomes Research

28 August 2015

Number of times this article has been viewed

\section{Maria M Fernandez' \\ Susan Hogue' \\ Ronald Preblick ${ }^{2}$ \\ Winghan Jacqueline Kwong ${ }^{2}$}

'RTI-Health Solutions, Market Access and Outcomes Strategy, Research Triangle Park, NC, ${ }^{2}$ Daiichi Sankyo, Inc., Health Economics \& Outcomes Research, Parsippany, NJ, USA
Correspondence: Maria Fernandez RTI-Health Solutions, Market Access and Outcomes Strategy, 3040 Cornwallis Road, PO Box 12194, Research Triangle Park, NC 27709-2194, USA

Tel + I $919485263 \mid$

Fax + I 91954I 7222

Email mfernandez@rti.org
Background: Venous thromboembolism (VTE) is the second most common medical complication and a cause of excess length of hospital stay. Its incidence and economic burden are expected to increase as the population ages. We reviewed the recent literature to provide updated cost estimates on VTE management.

Methods: Literature search strategies were performed in PubMed, Embase, Cochrane Collaboration, Health Economic Evaluations Database, EconLit, and International Pharmaceutical Abstracts from 2003-2014. Additional studies were identified through searching bibliographies of related publications.

Results: Eighteen studies were identified and are summarized in this review; of these, 13 reported data from the USA, four from Europe, and one from Canada. Three main cost estimations were identified: cost per VTE hospitalization or per VTE readmission; cost for VTE management, usually reported annually or during a specific period; and annual all-cause costs in patients with VTE, which included the treatment of complications and comorbidities. Cost estimates per VTE hospitalization were generally similar across the US studies, with a trend toward an increase over time. Cost per pulmonary embolism hospitalization increased from \$5,198-\$6,928 in 2000 to $\$ 8,764$ in 2010 . Readmission for recurrent VTE was generally more costly than the initial index event admission. Annual health plan payments for services related to VTE also increased from $\$ 10,804-\$ 16,644$ during the $1998-2004$ period to an estimated average of $\$ 15,123$ for a VTE event from 2008 to 2011. Lower costs for VTE hospitalizations and annualized all-cause costs were estimated in European countries and Canada.

Conclusion: Costs for VTE treatment are considerable and increasing faster than general inflation for medical care services, with hospitalization costs being the primary cost driver. Readmissions for VTE are generally more costly than the initial VTE admission. Further studies evaluating the economic impact of new treatment options such as the non-vitamin $\mathrm{K}$ antagonist oral anticoagulants on VTE treatment are warranted.

Keywords: deep vein thrombosis, pulmonary embolism, costs, pharmacoeconomics, resource utilization

\section{Introduction}

Venous thromboembolism (VTE) is a common vascular disease and a major cause of morbidity and mortality worldwide, with two major clinical manifestations: deep vein thrombosis (DVT), the most common manifestation; and pulmonary embolism (PE), the more serious manifestation and complication associated with a higher mortality rate than DVT. ${ }^{1,2}$ The overall incidence of VTE is similar in the USA (0.96-3.0 per 1,000) and Europe (0.75-2.69 per 1,000), with each region having up to one million individuals annually affected by DVT/PE. ${ }^{3}$ It has been estimated that, in each year, 
between $100,000^{4}$ and 296,000 ${ }^{5}$ VTE-related deaths occur in the USA and 370,000 VTE-related deaths occur in Europe. ${ }^{6}$ Because VTE disproportionately affects older patients, it is expected that these estimates will increase in the future as the population ages. ${ }^{7}$

VTE is estimated to be the second most common medical complication, the second most common cause of excess length of hospital stay (LOS), and the third most common cause of excess mortality. ${ }^{7}$ More than half of the cases are caused by hospitalization, of which $24 \%$ are attributable to surgery. ${ }^{8}$ The purpose of this review is to summarize the published literature on costs of VTE.

\section{Methods}

This literature review was conducted to answer a specific and targeted research objective, specifically, the economic burden of VTE from a global perspective. Medical literature databases, ie, PubMed, Embase, Cochrane Collaboration (including the National Health Service Economic Evaluation Database), Health Economic Evaluations Database, EconLit, and International Pharmaceutical Abstracts from 2003 to October 2014 were searched. We used a predefined search strategy, searching and screening published articles indexed with the Medical Subject Headings terms "venous thromboembolism", "venous thrombosis", "pulmonary embolism", "costs and cost analysis", "cost-benefit analysis", "economics, hospital", "economics, medical", "economics, nursing", "economics, pharmaceutical", and/or "cost of illness" to identify burden-of-disease studies, cost-of-illness studies, cost analyses, and studies reporting medication costs and resource utilization. Additional studies related to the topics of interest were also identified through searching bibliographies of related publications.

Original studies were included if they reported direct or indirect costs of the treatment or management of VTE (DVT, PE or both) to a health plan, health system, or hospital, including LOS, medication costs, and measures of health care utilization. Selected studies were prospective observational studies or retrospective health care data claims analyses or patient chart reviews. Reviews and studies reporting on economic models based on data from literature reviews or from studies previously published were excluded, but their references were reviewed to identify relevant primary studies. Studies focusing mainly on the quality of life of patients and caregivers without any costs reported were also excluded, along with conference abstracts that did not provide an explanation of the type of costs analyzed.
The literature search identified 524 titles and abstracts for screening. Of these, 446 were excluded, and 78 were retrieved as full-text and assessed. Twelve studies were included from database searching, and six studies were identified from reviewing bibliographies. A total of 18 studies met the inclusion criteria and are discussed in this review (Figure 1).

\section{Results}

Of the 18 studies identified, 13 reported data from the USA, four from Europe, and one from Canada. Three main VTE cost estimations were identified: cost per VTE hospitalization or per VTE readmission; cost for VTE management, usually reported annually or during a specific period; and annual allcause health care costs in patients with VTE, which includes the treatment of complications and comorbidities.

\section{Economic studies reporting costs of VTE treatment in the USA}

Table 1 presents a summary of the studies reporting data on the economic burden of VTE, DVT, or PE treatment in the USA. These studies used various study designs to assess the costs of managing VTE patients in the inpatient and/ or outpatient settings. We present them according to their reported costs.

\section{Cost perVTE hospitalization}

A total of seven studies assessed the economic burden of VTE in the inpatient setting from the hospital or health plan perspective.

\section{Hospital perspective}

Studies reporting costs from a hospital perspective were conducted in hospitals or were retrospective studies that used hospital databases. Knight et $\mathrm{al}^{9}$ analyzed data from inpatient records of 132 US hospitals from 1999 to 2000 available from the Premier Hospital Database to estimate the actual costs of care during hospitalization for VTE. Depending on whether unfractionated heparin (UFH) and/or low-molecular-weight heparin (LMWH) was used during hospitalization, mean total hospital costs ranged from $\$ 3,018$ to $\$ 5,040$ per admission for a primary DVT diagnosis and from $\$ 5,198$ to $\$ 6,928$ per admission for a primary $\mathrm{PE}$ diagnosis. A more recent study by Fanikos et $\mathrm{a}^{10}$ analyzing medical records of patients with PE from a US teaching hospital from 2003 to 2010 yielded a slightly higher cost estimate for PE hospitalization. The mean cost of hospital admission for a primary PE diagnosis was $\$ 8,764$. These studies consistently found that inpatient care for PE was more costly than for DVT from the hospital perspective. 


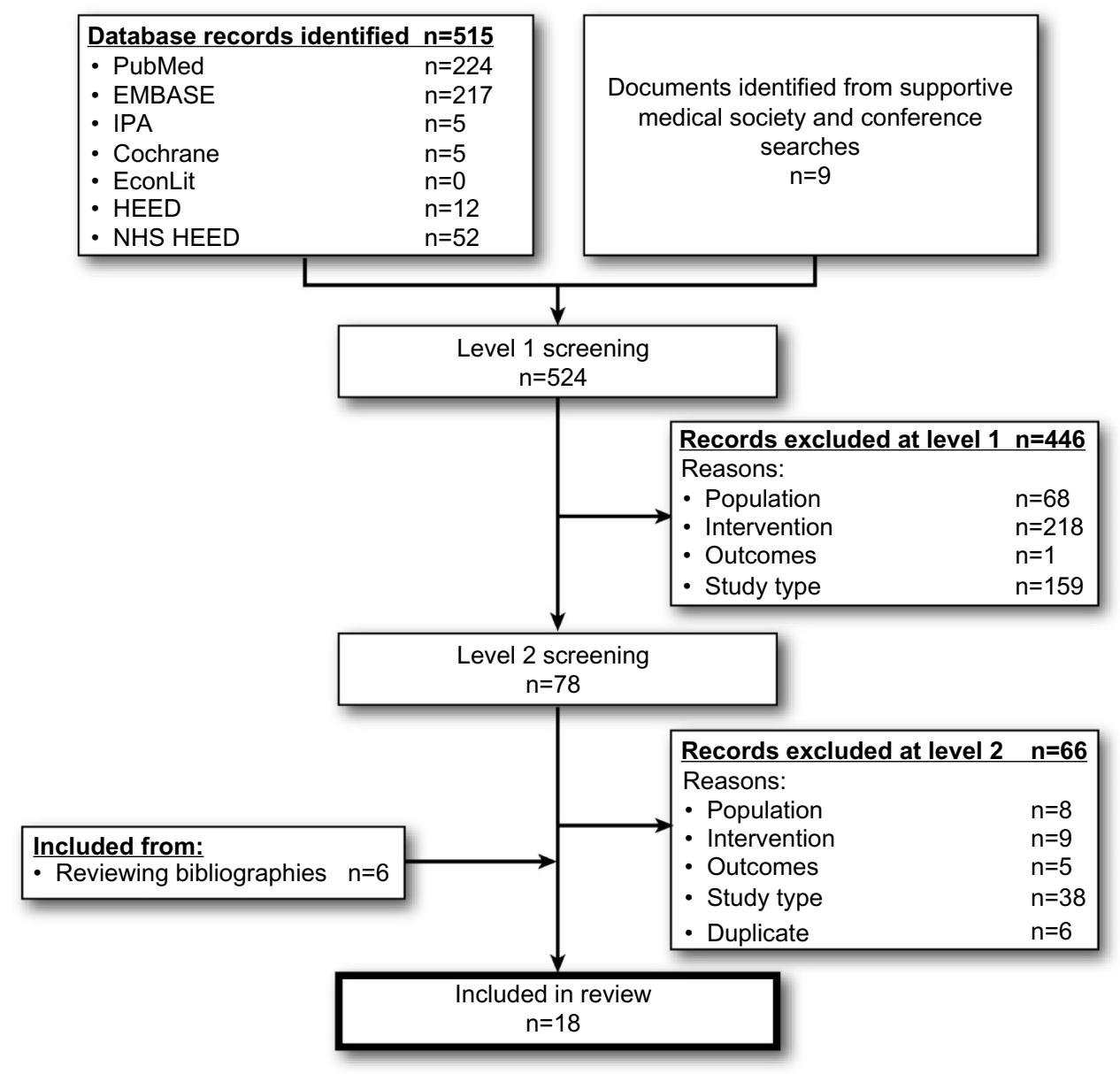

Figure I Flow diagram: economic analyses.

The fact that pharmacological treatment for VTE may affect hospitalization costs was confirmed by other studies. ${ }^{11-13}$ In a retrospective analysis of the MarketScan Hospital Drug Database (2005-2008) with data from 550 US hospitals, Bonafede et al found that total hospital charges per VTE admission were $\$ 409$ higher for patients treated with enoxaparin than for patients treated with fondaparinux. ${ }^{11}$ In an analysis of the Premier Perspective Database from 2002 to 2006, Merli et al ${ }^{12}$ concluded that although LMWH has higher drug acquisition costs than UFH, the use of LMWH for acute VTE treatment was associated with lower total direct medical costs per hospital discharge (estimated from time of index hospitalization to 90 days post discharge) than UFH ( $\$ 3,056$ versus $\$ 3,476 ; P<0.001)$ due to lower VTE readmission rates at 30 days (odds ratio $0.876 ; P<0.001$ ) and 90 days (odds ratio $0.895 ; P=0.0006$ ).

\section{Health plan perspective}

We identified three studies assessing the cost of inpatient VTE care from the health plan perspective. O'Brien and
Caro $^{14}$ estimated the average costs of various DVT management options from the perspective of US health payers in 1999 using resource use profiles and unit costs derived from several statewide inpatient, emergency department, and ambulatory care databases supplemented by national fee schedules, published reports, and peer-reviewed literature. A total of 1,077 US hospitals contributed to this data pool. The mean acute-care hospital costs, including emergency department, laboratory, pharmacy, diagnostic, and physician fees, were $\$ 5,779$ for a first DVT hospital stay and $\$ 6,946$, on average, for a DVT readmission. The increased costs of hospital readmissions did not appear to be due to an increase in LOS, but rather an increase of $\$ 264$ per day in hospital costs.

Other studies examined the cost of inpatient care from a health insurer perspective based on payment records in administrative claims databases. In a retrospective analysis of medical and pharmacy claims from patients with a primary or secondary VTE discharge diagnosis in two large US health care plans from 1998 to 2000, Bullano et a ${ }^{15}$ estimated the mean cost per index VTE event (including hospitalization 
Table I Economic studies reporting costs of treatment of venous thromboembolism in the USA

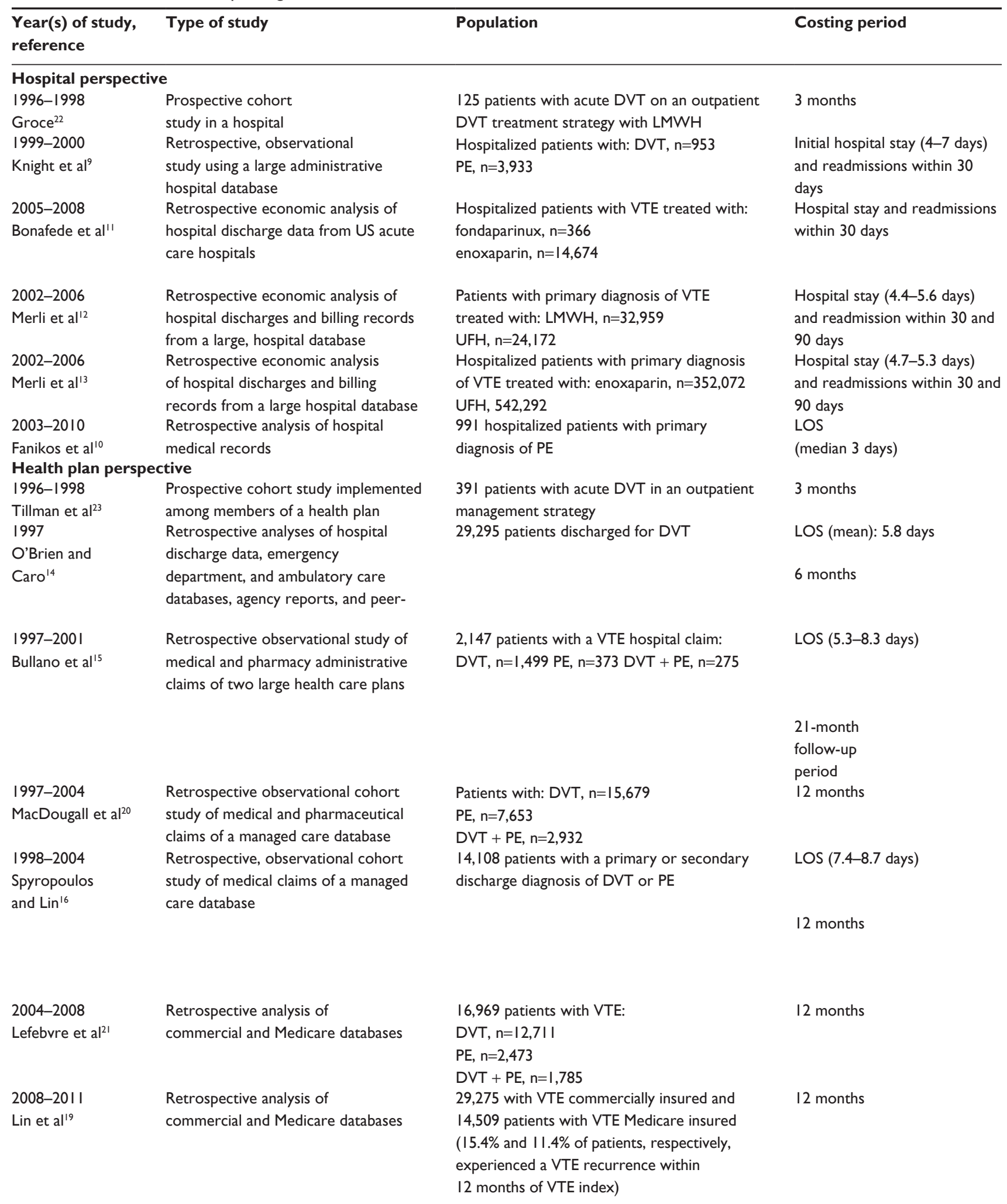

Note: All currencies are in US\$.

Abbreviations: DVT, deep vein thrombosis; LMWH, low-molecular-weight heparin; LOS, length of stay; PE, pulmonary embolism; UFH, unfractionated heparin; VTE, venous thromboembolism. 


\begin{tabular}{|c|c|c|c|c|}
\hline \multirow[t]{2}{*}{ Type of costs } & \multicolumn{4}{|l|}{ Costs } \\
\hline & VTE (DVT and/or PE) & DVT & PE & DVT + PE \\
\hline \multirow[t]{2}{*}{ Total mean direct costs } & & $\$ 965$ (outpatient) & & \\
\hline & & $\$ 3,436$ (inpatient) & & \\
\hline \multicolumn{4}{|l|}{ per stay } & \\
\hline Charges for index & Fondaparinux: $\$ 2,233$ & & & \\
\hline anticoagulant during & Enoxaparin: $\$ 2,497$ & & & \\
\hline admission and readmissions & After adjustment: fondaparinux & & & \\
\hline $\begin{array}{l}\text { within } 30 \text { days } \\
\text { Adjusted total inpatient direct }\end{array}$ & $\begin{array}{l}\text { was } \$ 409 \text { lower; } P=0.00 \text { I } \\
\text { UFH: } \$ 3,476.22\end{array}$ & & & \\
\hline $\begin{array}{l}\text { medical costs per hospital } \\
\text { discharge }\end{array}$ & LMWH: $\$ 3,056.42$ & & & \\
\hline Adjusted total inpatient direct & Enoxaparin: $\$ 5,363$ & & & \\
\hline $\begin{array}{l}\text { medical costs per hospital } \\
\text { discharge }\end{array}$ & UFH: $\$ 6,443$ & & & \\
\hline \multicolumn{3}{|l|}{ per stay } & & \\
\hline Total mean direct costs & & $\$ 1,868$ (outpatient) & & \\
\hline incurred by the health plan & & $\$ 4,696$ (inpatient) & & \\
\hline Total mean hospital cost per & & $\$ 5,779$ (first admission) & & \\
\hline stay (reported in 1999) & & $\$ 6,946$ (readmission) & & \\
\hline \multicolumn{5}{|l|}{$\begin{array}{l}\text { outpatient costs (reported } \\
\text { in 1999) }\end{array}$} \\
\hline Mean total hospital costs per & $\$ 8,331$ & $\$ 7,712$ & $\$ 9,566$ & $\$ 12,200$ \\
\hline $\begin{array}{l}\text { event paid by the health plan } \\
\text { to the provider }\end{array}$ & $\begin{array}{l}\$ 12,326 \text { (per recurrent } \\
\text { event with hospitalization) }\end{array}$ & $\begin{array}{l}\$ 11,419 \text { (per recurrent } \\
\text { event with hospitalization) }\end{array}$ & $\begin{array}{l}\$ 1 \mathrm{I}, 0 \mathrm{I} 4 \text { (per recurrent } \\
\text { event with } \\
\text { hospitalization) }\end{array}$ & $\begin{array}{l}\$ 19,237 \text { (per } \\
\text { recurrent event } \\
\text { with hospitalization) }\end{array}$ \\
\hline $\begin{array}{l}\text { Mean costs for recurrent } \\
\text { VTE, bleeding, and } \\
\text { anticoagulation treatment }\end{array}$ & $\begin{array}{l}\$ 14,975 \text { (per recurrent event } \\
\text { during follow-up period) }\end{array}$ & & & \\
\hline $\begin{array}{l}\text { Total mean adjusted annual all- } \\
\text { cause costs including recurrent } \\
\text { events (in 2004) }\end{array}$ & & $\$ 33,200$ & $\$ 31,270$ & $\$ 38,296$ \\
\hline Total mean hospital cost per & & $\$ 9,805$ (first admission) & $\$ 14,146$ (first & \\
\hline stay & & $\$ 11,862$ (readmission) & $\begin{array}{l}\text { admission) } \\
\$ 14,722 \text { (readmission) }\end{array}$ & \\
\hline $\begin{array}{l}\text { Total mean annual inpatient } \\
\text { and outpatient costs }\end{array}$ & & $\begin{array}{l}\$ 10,804 \text { (primary diagnosis) } \\
\$ 7,594 \text { (secondary diagnosis) }\end{array}$ & $\begin{array}{l}\$ 16,644 \text { (primary } \\
\text { diagnosis) } \\
\$ 13,018 \text { (secondary } \\
\text { diagnosis) }\end{array}$ & $\begin{array}{l}\$ 27,909 \\
\text { (secondary } \\
\text { diagnosis) }\end{array}$ \\
\hline $\begin{array}{l}\text { Total all-cause health care } \\
\text { cost per patient with VTE } \\
\text { per year (in 2008) }\end{array}$ & $\$ 33,531$ & & & \\
\hline Total annual VTE-related & $\$ 15,123$ (commercially insured) & & & \\
\hline care per patient & $\$ 38,59$ I (recurrent, commercially & & & \\
\hline & insured) $\$ 10,399$ (Medicare & & & \\
\hline & insured) $\$ 24,137$ (recurrent VTE, & & & \\
\hline & Medicare insured) & & & \\
\hline Total "all-cause" inpatient and & $\$ 36,918$ (commercially insured) & & & \\
\hline outpatient costs per patient & $\$ 82,110$ (recurrent VTE, & & & \\
\hline with VTE per year & commercially insured) & & & \\
\hline & $\begin{array}{l}\$ 31,203 \text { (Medicare insured) } \$ 55,982 \\
\text { (recurrent VTE, Medicare insured) }\end{array}$ & & & \\
\hline
\end{tabular}


and contiguous skilled facility care) to be $\$ 7,712 \pm \$ 18,339$ (median, \$3,131) for DVT, \$9,566 $\$$ \$13,512 (median, \$6,424) for PE, and $\$ 12,200 \pm \$ 24,038$ (median, $\$ 6,678$ ) for DVT + PE. The authors estimated that recurrent VTE events that require hospitalization may incur up to $48 \%$ higher costs than the initial event.

Higher cost estimates were found in another analysis using 1998-2004 data of the Integrated Health Care Information Services National Managed Care Database, which contained claims information from 30 managed care organizations. Spyropoulos and $\operatorname{Lin}^{16}$ found that mean inpatient cost per readmission for a recurrent DVT $(\$ 11,862)$ was significantly higher than the mean cost for the initial hospitalization $(\$ 9,805 ; P=0.006)$, but the mean inpatient cost per PE readmission $(\$ 14,722)$ was similar to the mean cost for the initial hospitalization $(\$ 14,146 ; P=0.38)$.

\section{Costs of VTE management}

Because VTE recurs frequently, especially within the first 6-12 months after the initial VTE event, ${ }^{17}$ it is important to understand the economic burden of VTE beyond initial hospitalization. Previous studies have shown that costs for the treatment of a recurrent VTE event are higher than those for treatment of a first VTE event. ${ }^{15,16}$ Complications during the follow-up period, such as bleeding and post-thrombotic syndrome (PTS), also result in higher overall costs for health care systems. ${ }^{18}$ In this section, we assess the economic burden of VTE care from a longer-term perspective that includes hospital costs for the treatment of the index event and follow-up costs, such as the cost of anticoagulation therapy and costs associated with management of complications. Some studies reported costs specific to the management of the VTE event and follow-up during a specific period, whereas other studies reported "all-cause" health care costs among patients with a VTE diagnosis, which may include costs for VTE-related complications and other comorbidities.

\section{Costs for treatment of initial VTE event}

\section{and post-acute care during a specific period}

O'Brien and Caro ${ }^{14}$ estimated the treatment cost of DVT from the perspective of US health payers using data from multiple sources under various assumptions. Applying unit cost estimates to the resource utilization profiles of patients discharged with a principal diagnosis of DVT from hospitals, emergency departments, and ambulatory care services in six US states (California, Florida, Maine, Maryland, Massachusetts, and Washington) in 1997, mean 6-month treatment costs for acute inpatient management and post- acute care were $\$ 10,072$ for all DVTs and $\$ 14,649$ DVTs with PE events.

The estimate from O'Brien and $\mathrm{Caro}^{14}$ was similar to the results of a later retrospective claims analysis from two US health plans using data from 1997 to 2001 by Bullano et al. Bullano et $\mathrm{al}^{15}$ estimated that during an average follow-up period of 21 months, the follow-up post-index costs for recurrent VTE, bleeding, warfarin \pm LMWH therapy, and international normalized ratio monitoring were $\$ 14,975$ per VTE event.

Spyropoulos and $\mathrm{Lin}^{16}$ used a similar costing approach to estimate the annualized VTE-related health care costs from a health plan perspective using more recent data. Only the portions of hospital facility costs that were attributable to VTE, outpatient VTE treatment-related drugs, and outpatient procedure claims associated with a VTE diagnosis and treatment-related procedures were included in the estimation of annualized health care cost after a VTE hospitalization. Using Integrated Health Care Information Services claims data from 1998 to 2004, total annual health care payments made to providers for VTE ranged from $\$ 7,594$ to $\$ 16,644$ depending on the type of VTE event and whether it was a primary or secondary diagnosis. The cost was primarily driven by hospitalization facility costs (ranging from $\$ 5,118$ to $\$ 13,223)$.

In a recent analysis of the Truven Health Analytics MarketScan Commercial and Medicare database from 2008 to 2010, Lin et $\mathrm{al}^{19}$ estimated that total annual payments for health care services associated with a VTE diagnosis 1 year following an index VTE event were greater for patients with a recurrence than for those without a recurrence $(\$ 38,591$ versus $\$ 15,123, P<0.001$ in commercially insured patients), when only claims associated with a VTE diagnosis and anticoagulant therapy were included in the cost estimation.

\section{Total all-cause health care costs in patients with VTE}

Three retrospective studies analyzed administrative claims data for different time periods to estimate all-cause health care costs for VTE patients, which include health care costs to treat VTE-related complications or other comorbidities patients may have. ${ }^{19,20,21}$ MacDougall et $\mathrm{al}^{20}$ analyzed data from the PharMetrics Patient-Centric Database from 1997 to 2004 and found that annualized mean adjusted all-cause direct medical costs of care, including pharmacy costs during and after the DVT/PE event, were \$33,200, \$31,270, and $\$ 38,296$ for patients with DVT, PE, or DVT and PE, respectively, in 2004 US dollars, compared with $\$ 2,800$ in matched controls without DVT or PE. Patients with PTS 
had higher annualized mean adjusted total costs $(\$ 47,596)$ compared with DVT and PE patients with no PTS $(\$ 35,929)$. The annual all-cause health care cost estimates for patients with VTE were similar to those from another retrospective analysis by Lefebvre et al, ${ }^{21}$ using 2004-2008 data from the Ingenix Impact database, in which patients with VTE were found to have significantly higher all-cause health care costs in the 12 months after an index VTE event compared with non-VTE patients $(\$ 33,531$ versus $\$ 17,590) .{ }^{21}$ Treatment possibly related to recurrent VTE, PTS, and other complications such as thrombocytopenia, superficial venous thrombosis, venous ulcer, pulmonary hypertension, stasis dermatitis, and venous insufficiency were higher in patients with VTE patients than in patients without VTE $(\$ 3,141$ versus $\$ 228$ ). The cost difference in possibly VTE-related care, $\$ 2,913$, represented one fifth of the per-patient-peryear all-cause cost difference between the VTE group and the no-VTE group.

Using more recent data from 2008 to 2010 , Lin et a ${ }^{19}$ found total payments for health care resource use for all causes, including inpatient and outpatient medical and pharmacy uses, to be significantly higher in patients with VTE who had VTE recurrence compared with those without a recurrent VTE $(\$ 82,110$ versus $\$ 36,918 ; P<0.001$, in commercially insured patients).

\section{Inpatient versus outpatient management of VTE}

Two studies evaluated the cost savings of outpatient DVT treatment from the hospital ${ }^{22}$ or the health plan $^{23}$ perspectives using actual cost data. In a hospital outpatient DVT program, ${ }^{22}$ designed so that patients with uncomplicated DVT would be discharged within 24-48 hours after diagnosis, 125 patients were treated for acute DVT primarily at home. The average length of hospitalization was reduced from 5.4 days before the program to 0.97 days. All patients received a total average of 5.23 days of enoxaparin treatment, 4.26 days treated on an outpatient basis and the rest as inpatient treatment. The hospital achieved a cost reduction of $\$ 2,470.68$ per patient (in 1998 dollars) in the 90 days after the index DVT event. In an outpatient DVT treatment program implemented in a large group model health maintenance organization, ${ }^{23} 391$ patients with a diagnosis of acute DVT were included from 1996 to 1998. After receiving the initial dose of enoxaparin in a medical facility, patients were allowed to return home, where they continued appropriate medication (warfarin or enoxaparin). All direct costs were determined from the perspective of the health plan and inflated to 1998 US dollars. Compared with hospitalization costs of inpatient UFH therapy for DVT, the outpatient treatment program reduced costs by $\$ 2,828$ per patient during the 2-year study period.

In a modeling study, O'Brien and Caro ${ }^{14}$ estimated that the 6-month treatment costs for inpatient management ranged from $\$ 3,906$ to $\$ 17,168$, depending on complication status. For outpatient management, the cost ranged from $\$ 2,394$ to $\$ 3,369$, depending on whether LMWH injections were administered by a health care professional or caregiver in a health care facility or at home.

\section{Economic studies reporting costs of VTE treatment in Canada and in European countries}

Comparing the cost of VTE across countries is challenging. Differences in treatment patterns and cost structures within health care systems yield variations in the cost of VTE treatment by country. Outpatient treatment of uncomplicated VTE has become more common since the availability of subcutaneous LMWH, and it has been proposed as an efficient and more cost-effective alternative to inpatient VTE treatment. ${ }^{24}$ Yet, adoption of outpatient VTE treatment varies considerably across countries and institutions, resulting in higher cost estimates driven by more inpatient services utilization when outpatient treatment is less common. ${ }^{25} \mathrm{We}$ identified five studies reporting costs for treating VTE, DVT, or PE in countries outside the USA (Table 2) ${ }^{26-30}$

\section{Cost perVTE hospitalization}

Two studies, one from Belgium and another from Italy, reported hospital costs per VTE event. Annemans et al ${ }^{27}$ determined the inpatient costs of $\mathrm{PE}$ from a health insurance cost perspective based on a retrospective chart review of a sample of 54 patients with PE from five centers in Belgium from January to June 1998; only medical resources related to PE were included and analyzed. The average total cost of PE was consistent among the centers $(€ 3,394)$. Wide variation in length of hospital stay was found (average, 14.6 days; median, 12.4 days). In Italy, Gussoni et $\mathrm{a}^{28}$ also reviewed patients' charts to assess the costs of VTE management and antithrombotic prophylaxis in 160 hospitalized patients with VTE and 160 hospitalized patients without VTE receiving prophylaxis. Only direct health costs were considered. The total median costs for VTE management were approximately four times higher than those for prophylaxis $(€ 1,348.68$ versus $€ 373.03)$. Human resources were the most important cost driver $(55.5 \%$ in the group with VTE and $65.7 \%$ the group without VTE). In the group of patients without VTE, direct costs for prophylaxis accounted for $4.5 \%$ of the total costs. 


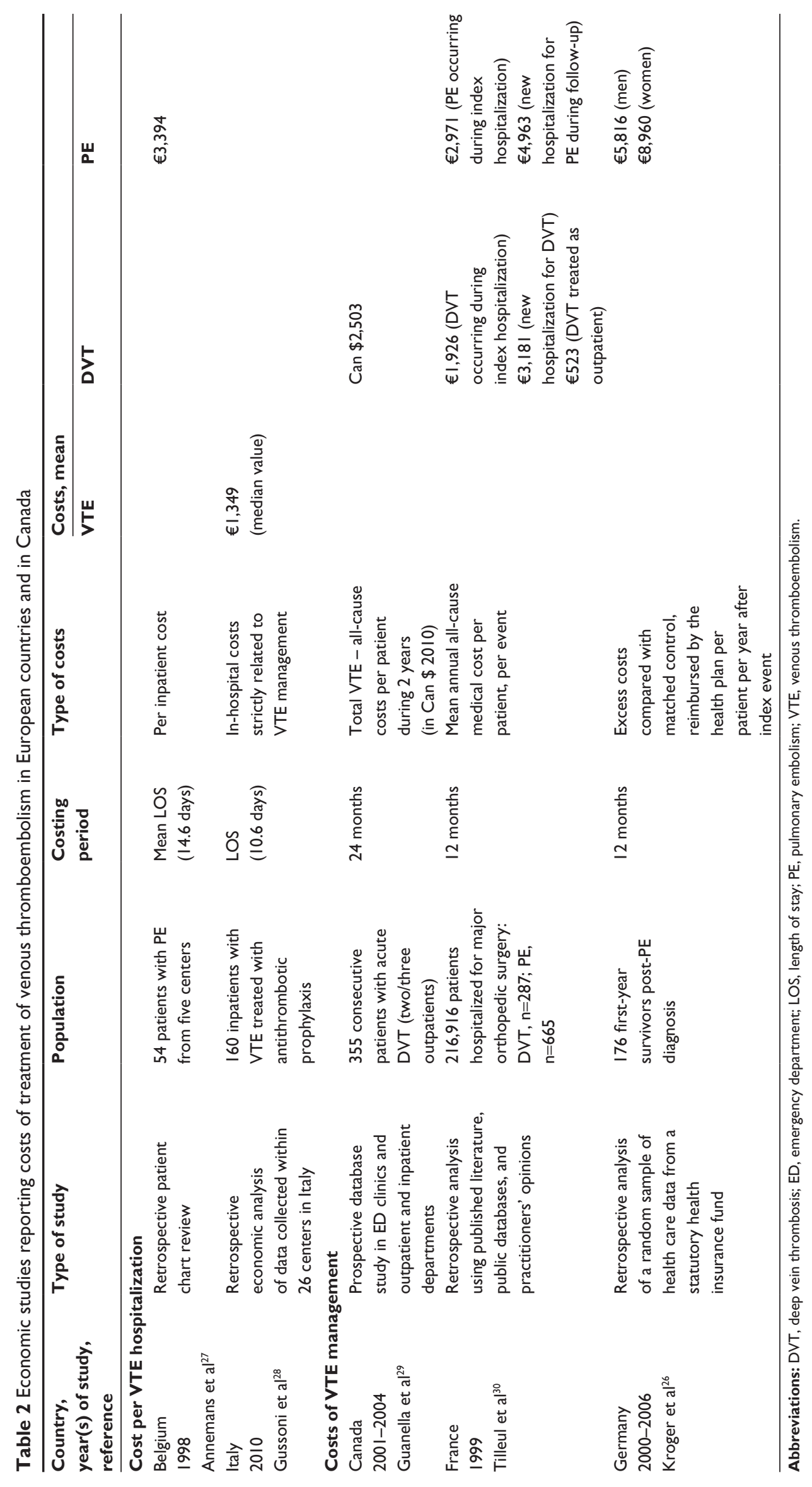




\section{Costs of VTE management}

We identified three studies that evaluated the cost of VTE treatment beyond initial events. In Canada, Guanella et al ${ }^{29}$ quantified medical and nonmedical costs related to DVT during 2 years following diagnosis in 355 consecutive patients with acute DVT recruited at seven Canadian hospital centers. Two thirds of the patients were treated as outpatients. The average total per patient cost during the 2-year period was Can $\$ 5,180$ (year 2010), with $51.6 \%$ of costs $(\$ 2,677$ ) attributable to use of nonmedical resources such as transport and loss of productivity and Can $\$ 2,503$ attributable to medical resources. Variables that predicted higher costs during the 2 years after DVT diagnosis included concomitant symptomatic PE at baseline, unprovoked DVT, development of PTS during follow-up, and management of DVT in the inpatient setting. In France, Tilleul et a $l^{30}$ used a model to estimate the annual direct costs of VTE in 1999 following major orthopedic surgery of the lower limb. Patients presenting with VTE were identified from the national disease-related group inpatient database. Only direct costs were considered, including inpatient and outpatient costs, which were estimated from health system databases. Annual costs per patient varied from $€ 523$ to $€ 4,963$, depending on whether the patient was treated on a completely outpatient basis, the type of VTE event, and whether the event was a new hospitalization.

Kroger et $\mathrm{al}^{26}$ estimated annual direct costs reimbursed by a German insurance fund in 2006 for patients with PE and patients with a hospital stay but without documentation of PE as controls. The total all-cause treatment cost (including outpatient physician services, outpatient prescriptions, inpatient care, medical devices, transport, and nursing care) for patients who survived the first year after a PE diagnosis in 2006 ( $n=176$ ) was $€ 21,351$ for men and $€ 20,275$ for women. Compared with matched controls without VTE, costs for patients who survived PE in the first year after a PE diagnosis were higher by $€ 8,960$ for female patients and $€ 5,816$ for male patients.

\section{Length of hospital stay}

LOS varied considerably across the studies depending on the type of cost and population studied (Table 3). In general, patients with both DVT and PE had longer mean hospital stays (7.4-9 days) than patients with PE (5.8-7.7 days) and patients with DVT (4.9-7 days). In the USA, mean LOS was longer for patients with readmissions (7.6-8.7 days). ${ }^{16}$ Mean LOS for patients with PE was considerably higher in Belgium (14.6 days) and Germany (21.4-23.6 days) than in the USA (6-7.7 days) and France (4.6-6.6 days). Pressure for health care cost containment, as well as differences in health system reimbursement and the level of adoption for outpatient VTE treatment in clinical practice, may contribute to the wide variation in LOS for DVT and PE seen between certain countries. As more treatment guidelines recommend outpatient treatment for uncomplicated VTE cases, VTE hospitalizations may be limited to the more complicated cases that necessitate a longer LOS. Regardless, VTE-related LOS is a key cost driver in the economic burden of this disease.

\section{Discussion}

Our present study provides a comprehensive review of published data for costs associated with VTE treatment in the USA, Canada, and Europe, covering the period from 1998 to 2014. Studies evaluating the economic burden of VTE used a variety of study designs, methodologies, and data sources, making it challenging to compare data across studies. We identified three main cost estimations for VTE: cost per VTE hospitalization or per VTE readmission; cost for VTE management, usually reported as annual cost or cost during a specific period: and annual all-cause health care costs in patients with VTE, which includes treatment of VTE and its complications and comorbidities.

Cost estimates per VTE hospitalization were generally similar across the US studies, with a trend toward increase over time. The most recent estimate of the hospital cost per PE admission based on data from 2010 was $\$ 8,764,{ }^{10}$ higher than the estimate of $\$ 5,198-\$ 6,928$ reported based on 2000 data. ${ }^{9}$ According to Fanikos et al,${ }^{10}$ nursing costs $(\$ 5,102$, including room and board) accounted for the largest component of the total $\$ 8,764$, followed by pharmacy costs ( $\$ 966)$, radiology costs (\$963), emergency department visits (\$625), and clinical laboratory costs $(\$ 567)$. Slightly higher costs for a PE hospitalization $(\$ 9,566)$ were estimated by Bullano et al ${ }^{15}$ using data from health care plans. The authors estimated that of these costs, $53.0 \%$ were attributable to room and board, $9.7 \%$ to both diagnostic/laboratory and pharmacy, $3.7 \%$ to the emergency department, and $23.8 \%$ to other resource centers. Hospitalizations for recurrent VTE had higher costs (from $\$ 11,014$ to $\$ 14,722$ for a $\mathrm{PE}$ readmission, and $\$ 11,419$ to $\$ 11,862$ for a DVT readmission). ${ }^{15,16}$ Spyropoulos and $\operatorname{Lin}^{16}$ found that hospital readmission was quite common among patients with VTE. Within 1 year of initial VTE hospitalization, $5.3 \%$ of patients with VTE as the primary discharge diagnosis and $14.3 \%$ of patients with VTE as the secondary discharge diagnosis were readmitted to the hospital. Overall, the studies consistently showed that the largest component of the total cost per VTE hospitalization was room and board 
Table 3 Economics studies reporting length of hospital stay for venous thromboembolism treatment in the USA and European countries

\begin{tabular}{|c|c|c|c|c|c|c|}
\hline \multirow{2}{*}{$\begin{array}{l}\text { Countryl } \\
\text { years }\end{array}$} & \multirow[t]{2}{*}{ Population } & \multicolumn{4}{|c|}{ Length of hospital stay (days), mean, unless otherwise noted } & \multirow[t]{2}{*}{ Reference } \\
\hline & & VTE & DVT & PE & DVT + PE & \\
\hline \multicolumn{7}{|l|}{ USA } \\
\hline 1997 & $\begin{array}{l}\text { Patients discharged } \\
\text { for DVT }\end{array}$ & & 5.8 & & & $\begin{array}{l}\text { O'Brien and } \\
\text { Caro' }\end{array}$ \\
\hline 1997-2004 & $\begin{array}{l}\text { Patients with DVT, } \\
P E \text {, and DVT + PE }\end{array}$ & & 7 & 6 & 9 & MacDougall et a ${ }^{20}$ \\
\hline $2003-2010$ & $\begin{array}{l}\text { Hospitalized patients } \\
\text { with primary } \\
\text { diagnosis of PE }\end{array}$ & & & 3 (median) & & Fanikos et al ${ }^{10}$ \\
\hline 1999-2000 & $\begin{array}{l}\text { Hospitalized patients } \\
\text { with DVT and PE } \\
\text { treated with different } \\
\text { anticoagulant therapies }\end{array}$ & & $\begin{array}{l}\text { UFH/LMWH/VKA: } \\
5.76 \\
\text { UFH/VKA: } 5.69 \\
\text { LMWH/VKA: } 4.40\end{array}$ & $\begin{array}{l}\text { UFH/LMWH/VKA: } \\
7.1 \text { I } \\
\text { UFH/VKA: } 6.68 \\
\text { LMWH/VKA: } 5.65\end{array}$ & & Knight et al ${ }^{9}$ \\
\hline 1998-2004 & $\begin{array}{l}\text { Patients with a primary } \\
\text { or secondary discharge } \\
\text { diagnosis of DVT or PE }\end{array}$ & & & $\begin{array}{l}7.7 \\
\text { (first admission) } \\
8.7 \\
\text { (readmission) }\end{array}$ & $\begin{array}{l}7.4 \\
\text { (first admission) } \\
7.6 \\
\text { (readmission) }\end{array}$ & $\begin{array}{l}\text { Spyropoulos } \\
\text { and } \operatorname{Lin}^{16}\end{array}$ \\
\hline $2008-2011$ & $\begin{array}{l}\text { Patients with VTE } \\
\text { commercially or } \\
\text { Medicare insured }\end{array}$ & $\begin{array}{l}3.4 \\
8-8.4 \text { (recurrent } \\
\text { VTE within I } 2 \text { months } \\
\text { of first event) }\end{array}$ & & & & Lin et al ${ }^{19}$ \\
\hline Belgium 1998 & Patients with PE & & & 14.6 & & Annemans et $\mathrm{a}^{27}$ \\
\hline France 1999 & $\begin{array}{l}\text { Patients hospitalized for } \\
\text { major orthopedic surgery } \\
\text { with DVT or PE }\end{array}$ & & $3.3-6.3$ & $4.6-6.6$ & & Tilleul et $\mathrm{a}^{30}$ \\
\hline Germany & Hospitalized patients & & & 21.4 (men) & & Kroger et $\mathrm{al}^{26}$ \\
\hline 2000-2006 & with PE & & & 23.6 (women) & & \\
\hline $\begin{array}{l}\text { Italy } \\
2010\end{array}$ & $\begin{array}{l}\text { Hospitalized patients } \\
\text { with VTE }\end{array}$ & 10.6 & & & & Gussoni et a $\mathrm{a}^{28}$ \\
\hline
\end{tabular}

Abbreviations: DVT, deep vein thrombosis; LMWH, low-molecular-weight heparin; PE, pulmonary embolism; UFH, unfractionated heparin; VKA, vitamin K antagonist; VTE, venous thromboembolism.

driven by LOS. The differences among these studies may be in the generation of the data, either from a hospital database or from a health care plan.

The two European studies that estimated costs per VTE hospitalization presented lower figures than the US studies (3,394 for a PE hospitalization in Belgium ${ }^{27}$ and 1,348.68 for a VTE hospitalization in Italy $^{28}$ ). Hospitalization cost is often driven by LOS and associated room and board resource utilization. However, we found LOS for PE patients to be longer in Belgium than in the USA. The cost differences may be due to differences in cost structures and variation in treatment patterns during the hospital stay. It is important to note that the Belgian and Italian studies had very small samples of patients (54 patients in the Belgian study and 160 patients in the Italian study) compared with the US studies. Therefore, it is difficult to draw conclusions and comparisons between costs in the USA and in European countries. However, studies in the USA and outside the USA consistently found that the costs for treatment of PE were higher than those for DVT.
In the USA, annual health plan payments for services related to VTE slightly increased from $\$ 10,804$ for a DVT event and $\$ 16,644$ for a PE event during the period 1998 to $2004^{16}$ to an estimated average of $\$ 15,123$ for a VTE event from 2008 to $2011 .{ }^{19}$ The studies from France, ${ }^{30}$ Germany, ${ }^{26}$ and $\mathrm{Canada}^{29}$ that report annual or ongoing costs for the treatment and management of VTE provide lower estimations than the US studies, which could be due to lower health care costs in these countries, different methodologies to estimate the cost, or different populations. For example, two thirds of the patients included in the Canadian study were treated as outpatients, which is most likely a reason for the lower cost estimates in this study. This study also found that nonmedical costs related to VTE were higher than medical costs.

Previous studies generally found hospital admission for recurrent VTE to be more costly than the initial event hospitalization, although one study found the cost of readmission for PE to be similar to the cost of initial hospitalization. ${ }^{16}$ Annual cost for patients with a recurrent VTE event increased 
from $\$ 14,975$ (for a follow-up period of 21 months) using data from 1997 to $2001^{15}$ to $\$ 38,591$ (for a follow-up period of 12 months) using data from 2008 to 2011 in a commercially insured population ${ }^{19}$ (or $\$ 24,137$ in a Medicare insured population). From 2000 to 2010, the Consumer Price Index for medical services increased from 266.0 to 411.208 (a 154\% increase). ${ }^{31}$ These results suggest that annual health plan payments for services related to VTE increased at a faster rate than general inflation for medical services.

Annual total health care costs in patients with VTE were comparable among the various US studies, from $\$ 33,200^{20}$ for a patient with DVT using data for 1997-2004 to $\$ 36,918$ for a VTE event using data for 2008-2011. ${ }^{19}$

The observed differences in LOS among the studies could be due to differences in reimbursement structure, treatment patterns, hospital protocols, and target populations. For example, in the French study, ${ }^{30}$ only patients hospitalized for major orthopedic surgery who developed DVT or PE were included, so the mean LOS for this population may not be comparable with the LOS of the other studies that included patients with unprovoked VTE. The availability of LMWH as an alternative to UFH for initial treatment of VTE during hospitalization and the growing evidence to support outpatient management of uncomplicated DVT may have contributed to reducing hospital use for VTE management over time. On the other hand, limiting hospitalization to complicated VTE cases may increase the average LOS for VTE hospitalizations. Differences in patient service reimbursement structures, whether capitated or on a per diem basis, may also have contributed to the differences in LOS among health care systems. Regardless, a core driver that consistently contributed to higher VTE-related economic burden was the level of inpatient service use.

Given the high economic burden of VTE, there is an unmet medical need for interventions to lower the cost of its treatment. These interventions could include diagnostic tests such as imaging techniques and procedures that facilitate diagnosis of VTE so that appropriate intervention can be provided to patients in a timely manner to lower the risk of further complications. ${ }^{32,33}$ In addition, the advent of new pharmacological options such as the new oral anticoagulants may provide a more convenient alternative to warfarin therapy to reduce the risk of VTE recurrences, along with a lower risk of bleeding complications. ${ }^{34-38}$ The economic value of these interventions should be evaluated, and those that have been shown to be cost-effective can be incorporated into treatment guidelines to support implementation in clinical practice. ${ }^{39}$

\section{Conclusion}

Costs for VTE treatment are considerable and have increased over time in the USA, with hospitalization costs, primarily LOS, as the main cost driver. Estimates are lower in European countries and in Canada; however, direct comparisons are not appropriate because very few studies were found in countries outside the USA, and these had small samples and different methodologies. Recurrent VTE that requires readmission could be up to $48 \%$ more costly than the initial event. Only direct medical costs are presented in this review. DVT symptoms such as pain, swelling, and ulceration can negatively impact a patient's daily activities. Several quality of life instruments are specifically designed to quantify the humanistic burden of VTE. ${ }^{40,41}$ Therefore, the cost data summarized in this paper is only one component of the overall burden of VTE.

Current treatment guidelines recommend anticoagulation therapy to reduce the risk of VTE recurrence. Warfarin has been the mainstay of oral anticoagulation for the past 50 years. Results from several clinical trials have suggested that novel oral anticoagulants may become therapeutic alternatives to warfarin in the near future. With the availability of new oral anticoagulant agents that do not require monitoring, it is very likely that more patients will be treated with these new agents. Further studies evaluating the economic impact of the new agents on the treatment of VTE are warranted.

\section{Disclosure}

Funding for this work was provided by Daiichi Sankyo, Inc. RP and WJK are employees of Daiichi Sankyo, Inc. The authors report no other conflicts of interest in this work.

\section{References}

1. Goldhaber SZ, Bounameaux H. Pulmonary embolism and deep vein thrombosis. Lancet. 2012;379:1835-1846.

2. White RH. The epidemiology of venous thromboembolism. Circulation. 2003;107:I4-I8.

3. Liu X, Phatak H, Dillon R, Mitchell SA. Epidemiology and mortality of venous thromboembolism across patient populations: a systematic literature review. Presented at the ISPOR 18th Annual International Meeting, New Orleans, LA, USA. May, 2013. Available from: http://www. ispor.org/research_pdfs/43/pdffiles/PCV5.pdf. Accessed September 17, 2013.

4. Galson SK. The surgeon general's call to action to prevent deep vein thrombosis and pulmonary embolism. 2008. Available from: http://www. surgeongeneral.gov/news/2008/09/pr20080915.html. http://www.ncbi. nlm.nih.gov/books/NBK44178/. Accessed January 8, 2015.

5. Heit JA, Cohen AT, Frederick A. Anderson FA; VTE Impact Assessment Group. Estimated annual number of incident and recurrent, non-fatal and fatal venous thromboembolism (VTE) events in the US. Blood (ASH Annual Meeting Abstracts) 2005 106: Abstract 910.

6. Cohen AT, Agnelli G, Anderson FA, et al; VTE Impact Assessment Group in Europe (VITAE). Venous thromboembolism (VTE) in Europe: the number of VTE events and associated morbidity and mortality. Thromb Haemost. 2007;98:756-764. 
7. Geerts WH, Bergqvist D, Pineo GF, et al. Prevention of venous thromboembolism: American College of Chest Physicians evidence-based clinical practice guidelines, 8th edn. Chest. 2008;133:381S-453S.

8. Heit JA, O'Fallon WM, Petterson TM, et al. Relative impact of risk factors for deep vein thrombosis and pulmonary embolism: a populationbased study. Arch Intern Med. 2002;162:1245-1248.

9. Knight KK, Wong J, Hauch O, Wygant G, Aguilar D, Ofman JJ. Economic and utilization outcomes associated with choice of treatment for venous thromboembolism in hospitalized patients. Value Health. 2005;8:191-200.

10. Fanikos J, Rao A, Seger AC, Carter D, Piazza G, Goldhaber SZ. Hospital costs of acute pulmonary embolism. Am J Med. 2013;126:127-132.

11. Bonafede MM, Shorr AF, Johnson BH, Horblyuk R. Fondaparinux is economically non-inferior to enoxaparin for the treatment of venous thromboembolism. Value Health. 2009;12:A142.

12. Merli G, Ferrufino C, Lin J, Hussein M, Battleman D. Hospital-based costs associated with venous thromboembolism treatment regimens. J Thromb Haemost. 2008;6:1077-1086.

13. Merli G, Ferrufino CP, Lin J, Hussein M, Battleman D. Hospital-based costs associated with venous thromboembolism prophylaxis regimens. J Thrombosis Thrombolysis. 2010;29:449-458.

14. O'Brien JA, Caro JJ. Direct medical cost of managing deep vein thrombosis according to the occurrence of complications. Pharmacoeconomics. 2002;20:603-615.

15. Bullano MF, Willey V, Hauch O, Wygant G, Spyropoulos AC, Hoffman L. Longitudinal evaluation of health plan cost per venous thromboembolism or bleed event in patients with a prior venous thromboembolism event during hospitalization. J Manag Care Pharm. 2005; 11:663-673.

16. Spyropoulos AC, Lin J. Direct medical costs of venous thromboembolism and subsequent hospital readmission rates: An administrative claims analysis from 30 managed care organizations. J Manag Care Pharm. 2007;13:475-486.

17. Heit JA, Mohr DN, Silverstein MD, Petterson TM, O'Fallon WM, Melton LJ 3rd. Predictors of recurrence after deep vein thrombosis and pulmonary embolism: a population-based cohort study. Arch Intern Med. 2000;160:761-768.

18. Ruppert A, Steinle T, Lees M. Economic burden of venous thromboembolism: a systematic review. J Med Econ. 2011;14:65-74.

19. Lin J, Preblick R, Lingohr-Smith M, Kwong WJ. Incremental healthcare resource utilization and economic burden of venous thromboembolism recurrence from a US payer perspective. J Manag Care Pharm. 2014;20:174-186

20. MacDougall DA, Feliu AL, Boccuzzi SJ, Lin J. Economic burden of deep-vein thrombosis, pulmonary embolism, and post-thrombotic syndrome. Am J Health-Syst Ph. 2006;63(20 suppl):S5-S15.

21. Lefebvre P, Laliberté F, Nutescu EA, et al. All-cause and potentially disease-related health care costs associated with venous thromboembolism in commercial, Medicare, and Medicaid beneficiaries. J Manag Care Pharm. 2012;18:363-374.

22. Groce III JB. Patient outcomes and cost analysis associated with an outpatient deep venous thrombosis treatment program. Pharmacotherapy. 1998;18:175S-180S.

23. Tillman DJ, Charland SL, Witt DM. Effectiveness and economic impact associated with a program for outpatient management of acute deep vein thrombosis in a group model health maintenance organization. Arch Intern Med. 2000;160:2926-2932.

ClinicoEconomics and Outcomes Research

\section{Publish your work in this journal}

ClinicoEconomics \& Outcomes Research is an international, peerreviewed open-access journal focusing on Health Technology Assessment, Pharmacoeconomics and Outcomes Research in the areas of diagnosis, medical devices, and clinical, surgical and pharmacological intervention. The economic impact of health policy and health systems
24. Yeager BF, Matherny SC. Low-molecular-weight heparin in outpatient treatment of DVT. Am Fam Physician. 1999;59(4):945-952.

25. Blattler W, Gerlach HE. Implementation of outpatient treatment of deepvein thrombosis in private practices in Germany. Eur J Vasc Endovasc Surg. 2005;30(3):319-324.

26. Kroger K, Kupper-Nybelen J, Moerchel C, Moysidis T, Kienitz C, Schubert I. Prevalence and economic burden of pulmonary embolism in Germany. Vasc Med. (United Kingdom) 2012;17:303-309.

27. Annemans L, Robays H, Bruart J, Verstraeten P. Variation in medical resource utilization in the management of pulmonary embolism in Belgium. Acta Clin Belg. 2002;57:11-18.

28. Gussoni G, Foglia E, Frasson S, et al., on behalf of the FADOI Permanent Study Group on Clinical Governance. Real-world economic burden of venous thromboembolism and antithrombotic prophylaxis in medical inpatients. Thromb Res. 2013;131:17-23.

29. Guanella R, Ducruet T, Johri M, et al. Economic burden and cost determinants of deep vein thrombosis during 2 years following diagnosis: a prospective evaluation. J Thromb Haemost. 2011;9:2397-2405.

30. Tilleul P, LaFuma A, Colin X, Ozier Y. Estimated annual costs of prophylaxis and treatment of venous thromboembolic events associated with major orthopedic surgery in France. Clin Appl Thromb-Hem. 2006;12:473-484

31. Bureau of Labor Statistics. United States Department of Labor. Archived Consumer Price Index detailed report information. Available from: http://www.bls.gov/cpi/cpi_dr.htm\#2001. Accessed March 28, 2014.

32. Galeandro AI, Quistelli G, Scicchitano P, et al. Doppler ultrasound venous mapping of the lower limbs. Vasc Health Risk Manag. 2012;8:59-64.

33. Galeandro AI, Scicchitano P, Zito A, et al. A three-dimensional electronic report of a venous echo color Doppler of the lower limbs: MEVeC $^{\circledR}$. Vasc Health Risk Manag. 2014;10:549-555.

34. Prins $\mathrm{MH}$, Lensing AW, Bauersachs R, et al. Oral rivaroxaban versus standard therapy for the treatment of symptomatic venous thromboembolism: a pooled analysis of the EINSTEIN-DVT and PE randomized studies. Thromb J. 2013;11(1):21.

35. Agnelli G, Buller HR, Cohen A, et al. Oral apixaban for the treatment of acute venous thromboembolism. $N$ Engl J Med. 2013;369(9):799-808.

36. Büller HR, Décousus H, Grosso MA, et al. Edoxaban versus warfarin for the treatment of symptomatic venous thromboembolism. $N$ Engl $J$ Med. 2013;369(15):1406-1415.

37. Schulman S, Kakkar AK, Goldhaber SZ, et al. Treatment of acute venous thromboembolism with dabigatran or warfarin and pooled analysis. Circulation 2014;129(7):764-772.

38. Schulman S, Kearon C, Kakkar AK, et al. Dabigatran versus warfarin in the treatment of acute venous thromboembolism. $N$ Engl J Med. 2009;361(24):2342-2352.

39. Anderson JL, Heidenreich PA, Barnett PG, et al. ACC/AHA Statement on Cost/Value Methodology in Clinical Practice Guidelines and Performance Measures: A Report of the American College of Cardiology/American Heart Association Task Force on Performance Measures and Task Force on Practice Guidelines. Circulation. 2014;129(22):2329-2345

40. Sánchez FSL, Bolumburu AAA. [Quality of life and venous thromboembolic disease]. [Article in Spanish]. Med Clin (Barc). 2008 Nov;131 Suppl 2:37-41.

41. Klok FA, van Kralingen KW, van Dijk AP, et al. Quality of life in long-term survivors of acute pulmonary embolism. Chest. 2010;138: $1432-1440$.

\section{Dovepress}

organization also constitute important areas of coverage. The manuscript management system is completely online and includes a very quick and fair peer-review system, which is all easy to use. Visit $\mathrm{http}: / /$ www.dovepress.com/testimonials.php to read real quotes from published authors. 